\title{
Intelligent Systems Applied to Optimize Building's Environments Performance
}

\author{
E. Sierra ${ }^{1}$, A. Hossian ${ }^{2}$, D. Rodríguez ${ }^{3}$, M. García-Martínez ${ }^{4}$, P. Britos ${ }^{5}$, \\ and R. García-Martínez ${ }^{6}$
}

\begin{abstract}
By understanding a building as a dynamic entity capable of adapting itself not only to changing environmental conditions but also to occupant's living habits, high standards of comfort and user satisfaction can be achieved. An intelligent system architecture integrating neural networks, expert systems and negotiating agents technologies is designed to optimize intelligent building's performance. Results are promising and encourage further research in the field of AI applications in building automation systems.
\end{abstract}

\section{Introduction}

According to the latest definitions internationally accepted for an "intelligent building", this is a building highly adaptable to the changing conditions of its

\footnotetext{
1 E. Sierra

Engineering School, Comahue University. esierra@uncoma.edu.ar

2 A. Hossian

Engineering School, Comahue University. Intelligent Systems Lab. FI-UBA ahossian@uncoma.edu.ar 3 D. Rodriguez

Software \& Knowledge Eng. Center. Buenos Aires Institute of Technology. drodrigu@itba.edu.ar

${ }^{4}$ M. Garcia-Martinez

School of Architecture. University of Buenos Aires.mgm@fadu.uba.ar

${ }^{5}$ P. Britos

Software \& Knowledge Eng. Center. Buenos Aires Institute of Technology. pbritos@itba.edu.ar

${ }^{6}$ R. Garcia-Martinez

Software \& Knowledge Engineering Center. Buenos Aires Institute of Technology. rgm@itba.edu.ar
}

Please use the following format when citing this chapter:

Sierra, E., Hossian, A., Rodríguez, D., García-Martínez, M., Britos, P. and García-Martínez, R., 2008, in IFIP International Federation for Information Processing, Volume 276; Artificial Intelligence and Practice II; Max Bramer; (Boston: Springer), pp. 237244. 
environment [1]. But, in an overall concept of comfort, the idea of adaptation to changing environmental conditions may be not enough. Building systems are constructed in order to provide comfortable living conditions for the persons who live in them. It is well known that people usually differ in their personal perceptions of comfort conditions. To some extent, the sensation of comfort is an individual one and it is normally affected by cultural issues.

Thus, the idea behind this research is to find techniques based on artificial intelligence in order to provide design recommendations for comfort systems in buildings so that these buildings can also be highly adaptable in terms of the comfort conditions desired by their users. In a few words, a building must "learn" to change its performance not only as a function of environmental conditions, but also as a consequence of preferences set by the people who live in it.

\section{The proposed Intelligent System Architecture}

According to the latest trends in the field, intelligence in building systems tends to be distributed [2]. The proposed intelligent system architecture is shown in Figure 1. There is a main computer where the functions of monitoring, visualizing and recording parameters is carried out while the regulation functions are left to the local controllers located throughout the building [3]. These controllers are responsible for taking over local control tasks in the zone they serve.

To accomplish its function, the centralized computer contains a database that keeps track of relevant information concerning building user's preferences. For instance, this database keeps records of time, date, number of persons in a room, current temperature and humidity values, as well as temperature and humidity values desired by users. In order to do this, temperature and humidity input panels are located in the different rooms. Each user can eventually set them to what he or she thinks is an ideal comfort condition. As comfort perception is an individual sensation, the database in the main computer keeps track of every individual requirement.

The information contained in the user's requirements database for a given room is applied to a neural network of the self organizational maps of Kohonen (SOM) [4] and [5] type, which is used to cluster all the user's requirements and discard all those groups of requirements which are not relevant in terms of their approximation to the main cluster of preferences. Once a unique group of requirements is selected, their values are applied as input to a program which provides the limits as well as the average value for a particular environmental variable.

This value is used as reference or set-point for the local control strategies set by an expert system which runs on the main computer. This expert system takes decisions concerning control strategies which are used to activate, deactivate or tune the individual controllers. The information about relevant occupancy and setting conditions, as well as the final values of environmental variables is used to train a multi-layer neural network which outcomes will provide ideal 
environmental values in case of absence of occupants or of preference information given by them.

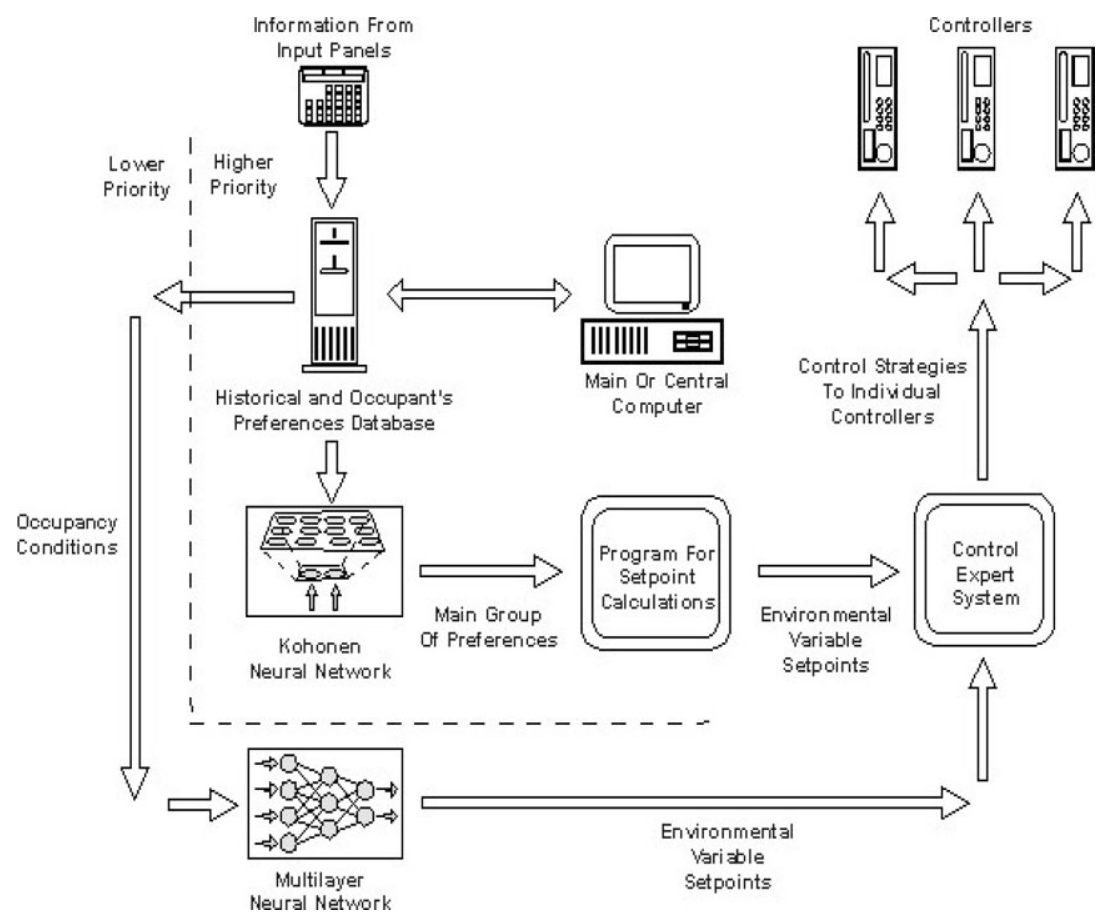

Fig.1. Intelligent System Architecture where the negotiating agent resides in main computer

In any case, set-points assigned to comfort variables provided by the analysis of user's desired environmental conditions is given priority over any automatic calculation of these conditions.

\section{Energy saving conditions}

A very important issue in intelligent buildings technology is related to energy saving policies [6]. Optimisation procedures carried out to cut off energy consumption rates are not only justified in terms of operation costs reduction but also because of the environmental benefits implied in the adoption of energy saving strategies.

In order to accomplish previously mentioned optimization procedures, an expert system [7] containing rules that perform energy saving strategies is set up in the central computer. However, it is necessary to verify if the rules defined in 
the energy saving expert system may eventually alter the comfort conditions established by the control strategy expert system. As it is shown on Figure 2, there is an intelligent negotiation agent [8], [9] and [10] which runs in the central computer created to determine whether the application of energy saving strategies will: a) not affect current comfort conditions in a given space (not affected) b) affect current comfort conditions but within the limits found by the SOM neural network based upon preference information provided by occupants (partially affected) c) affect current comfort conditions beyond the limits set by occupant's requirements (fully affected).

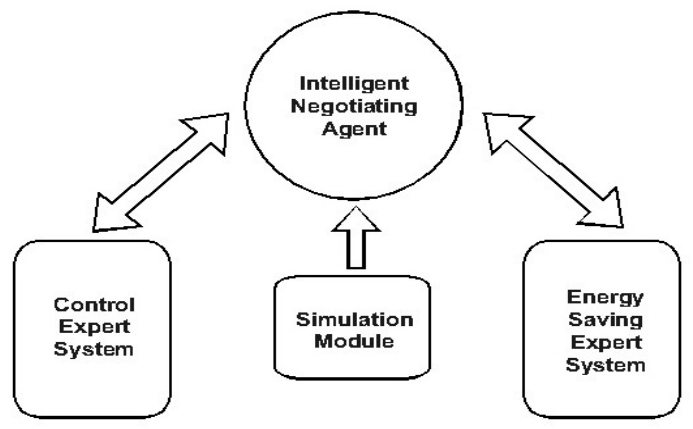

Fig. 2. Negotiation Control and Energy Saving Rules

The policy applied by the intelligent negotiation agent in the different situations mentioned earlier can be summarized as follows:

1. If comfort conditions are not affected, rules defining energy saving strategies are given the highest priority

2. If comfort conditions are partially affected, rules defining energy saving strategies are given an intermediate priority, just lower than the priority given to the rules that regulate the operation of main control actuators.

3. If comfort conditions are fully affected, rules defining energy saving strategies are given the lowest priority.

To be more descriptive in terms of how the inference engine runs, the intelligent negotiation agent was given a number of rules which express the desired energy saving policy (constraints) based on the building conditions. The occurrence of certain events inside the building (e.g. a temperature raises above a permitted upper limit) will trigger the appropriate rule within the agent.

The agent executes the rule(s), with the purpose of readjusting the environmental conditions to some preferred set of values. The triggered rule(s) will cause a set of actions to be immediately executed. After the previously described negotiation policy has been applied, the control expert system located in the main central computer has an updated rule base which can be used to set up the operation mode of local controllers (on, off, normal) and tune them 
accordingly, for example, by determining the appropriate set-point for the control variable.

\section{An Example}

With the purpose of providing an example that illustrates the functionality of the proposed intelligent system, the operation of the air - handling system depicted in Figure 3 will be described. It is assumed that the HVAC engineer has already designed the air handler in terms of laying out the ductwork, appropriately sizing the fan and heating and cooling coils, and selecting the proper dampers, damper actuators and motor contactor. From this design a system diagram has been constructed as shown in Figure 3.

The designations DA and VA stand for damper and valve actuators, respectively, $\mathrm{C}$ is for electrical contactor and $\mathrm{H} / \mathrm{C}$ and $\mathrm{C} / \mathrm{C}$ represent the heating and cooling coils. When building zone building served by the air -handler is "occupied", i.e., the current date and time fall within a certain schedule, the system is said to be in occupied mode. In this mode, the fan is started and the heating and cooling valves and dampers are modulated so as to maintain the setpoint temperature in the zone.

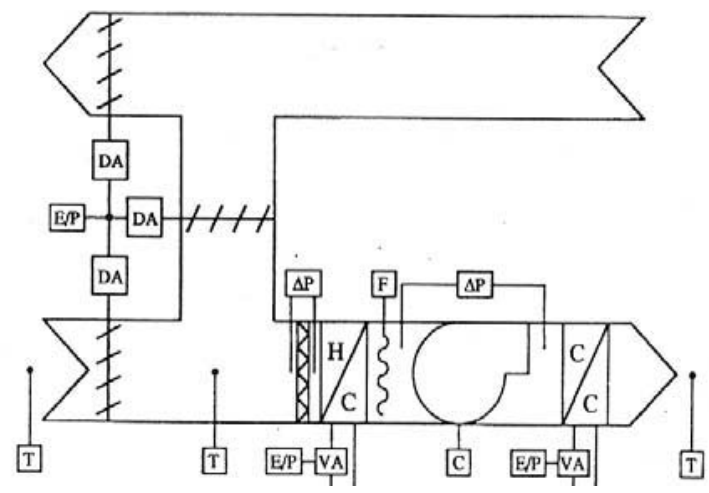

Fig. 3. System Diagram for the Air Handler

This is called the "normal" operating condition. Control strategies describe how specific subsystems are to be controlled. Thus, some of the rules contained in the rule base of the control expert system will stated as follows: 


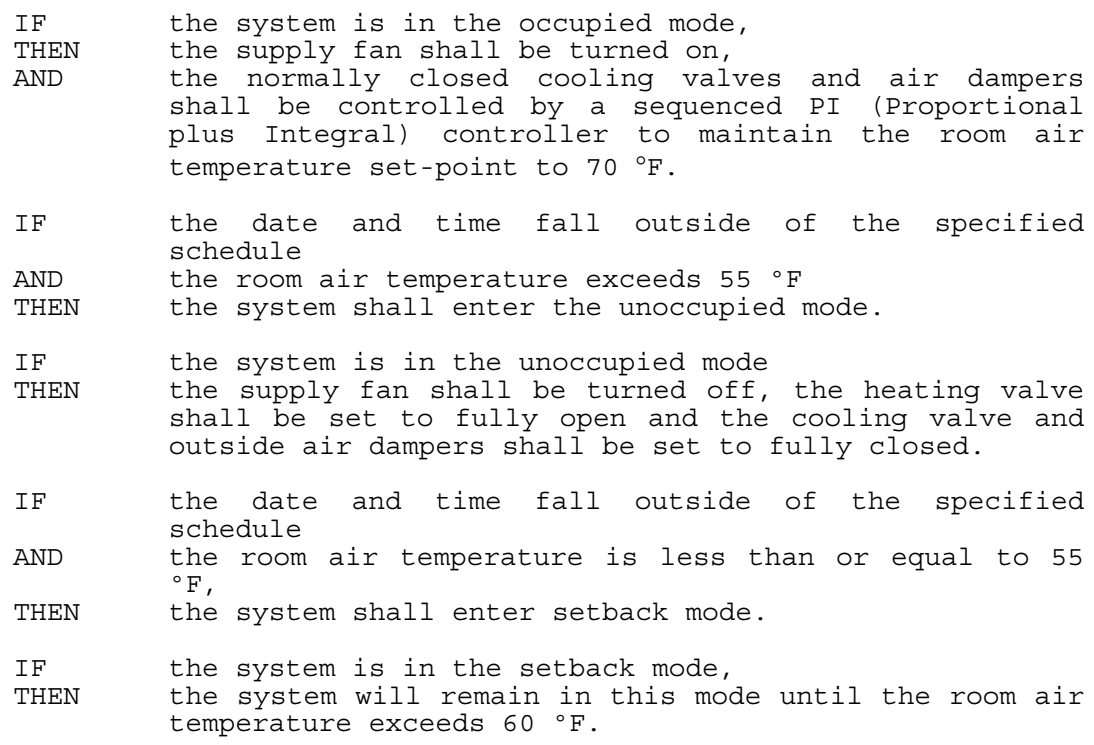

Energy saving strategies were designed in order to diminish energy consumption levels while keeping a satisfying response to the building energy demand profiles. Therefore, some of the rules contained in the rule base of the energy saving expert system can be enunciated in the following manner:

\section{Dry Bulb Economizer Control:}

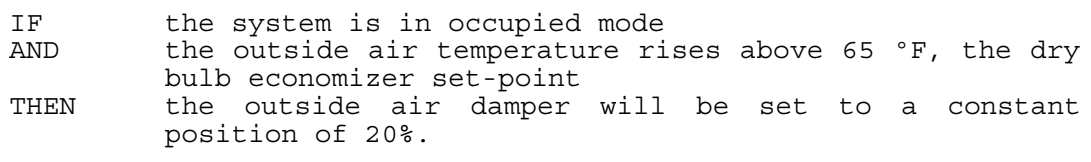

\section{Mixed Air Low Limit Control:}
IF the system is in occupied mode
AND the mixed air temperature drops from 40 to $30{ }^{\circ} \mathrm{F}$,
THEN a proportional (P) control algorithm shall modulate the outside air dampers from 100 to $0 \%$. Mixed air low limit control shall have priority over dry bulb economizer control.

Free cooling:

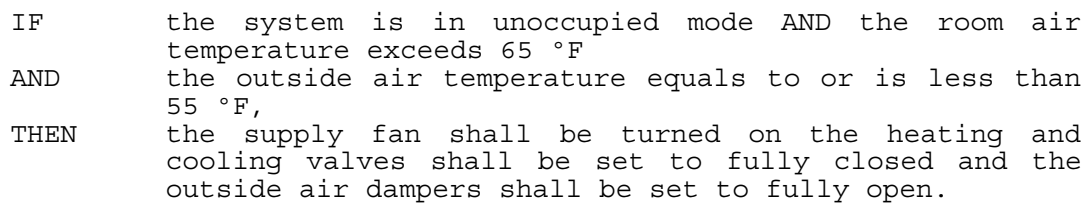


As previously stated, the system tries to capture the occupants' preferences by modifying the set-points of control variables to users' demands.

\section{Implementation and Results}

A prototype of the proposed intelligent system has been implemented in CLIPS, a tool for developing expert systems. Neural network and negotiating agent algorithms have been programmed in $\mathrm{C}++$. The system prototype has been tested in the building of the Ministry of Education, located in the city of Neuquén, Argentina. This building has been designed with a high degree of intelligence.

After almost a year of continuous tuning and adjusting procedures, the most updated prototype of the system was put to work. The people who work in this public building was strongly encouraged to set comfort parameters in the input control panels that were installed for this purpose in different building zones. The comments of users who admitted positive changes in comfort conditions were confirmed by a survey. The survey outcomes were: $75 \%$ percent of users were very satisfied with the performance of the new system, $20 \%$ were just satisfied and $5 \%$ not satisfied. Such results encourage advancing in this direction of optimizing the operative and control strategies carried out by the developed system.

\section{Conclusions}

Techniques of artificial intelligence have been used in many decision, control and automation systems in the last twenty years. Building systems have not been an exception. In this direction, the intelligent system that is proposed in this article tries to contribute in the field of intelligent buildings optimization, by transforming them in a dynamic space, with high standards of comfort and occupant's satisfaction. In this sense, the ability inherent to intelligent systems that are capable of learning from their own environment plays a very important role in the achievement of these building performance optimization goals. Furthermore, results obtained as a consequence of the proposed system implementation are very encouraging. Thus, further research and development work in the field deserves particular attention.

\section{References}

1. Krainier, A. Toward smart buildings, Architectural Assn. Graduate School, Environment \& Energy Studies Program. (1996).

2. So, A. Intelligent building systems, Kluwer Academic Press. (1999). 
3. Wong, K. The Intelligent Building Index: IBI manual: version 2.0, Hong Kong: Asian Institute of Intelligent Buildings. (2001).

4. Rich E. and Kevin, K. Introduction to Artificial Networks. Mac Graw-Hill. Publications. (1991).

5. Hilera J. and Martínez V. Redes Neuronales Artificiales. Fundamentos, modelos y aplicaciones. RA-MA, Madrid. (1995).

6. Sierra, E., Hossian, A., Labriola, C., García Martínez R. Optimal Design of Constructions: A Preliminary Model. Proceedings of the World Renewable Energy Congress (WREC 2004) - Denver, Colorado, Estados Unidos. (2004).

7. García Martínez, R. and Britos, P. Ingeniería de Sistemas Expertos. Editorial Nueva Librería. 649 páginas. ISBN 987-1104-15-4. (2004).

8. Allen, J. F, Kautz, H., Pelavin, R. N., and Tenenberg, J.D. Reasoning About Plans. Morgan Kaufmann Publishers, Inc. San Mateo, California. (1991).

9. Conry S. E., Meyer R. A., and Lesser V.R. Multistage negotiation in distributed planning. En Bond A and Gasser, L. [Eds] Readings in Distributed Artificial Intelligence. Morgan Kaufmann Publishers, Inc. San Mateo, California. (1988).

10. Ferber J. and Drougol A. Using reactive multiagent systems in simulation and problem solving. In Avouris, N.M and Gasser L. [Eds], Distributed Artificial Intelligence: Theory and Praxis. Kluwer Academic Press. (1992). 